\title{
Ovarian huge serous cystadenoma with torsion in adolescent girl: a case report
}

\author{
Shweta Avinash Khade*, Sneha Shirodkar
}

Department of Obstetrics and Gynecology, Topiwala National Medical College and BYL Nair Charitable Hospital, Mumbai central, Maharashtra, India

Received: 05 January 2017

Revised: 19 January 2017

Accepted: 04 February 2017

\section{*Correspondence:}

Dr. Shweta Avinash Khade,

E-mail: drshwetam2009@gmail.com

Copyright: ( $)$ the author(s), publisher and licensee Medip Academy. This is an open-access article distributed under the terms of the Creative Commons Attribution Non-Commercial License, which permits unrestricted non-commercial use, distribution, and reproduction in any medium, provided the original work is properly cited.

\begin{abstract}
In adolescent Ovarian cysts are an extremely common gynaecological problem. Majority of ovarian cysts are benign with few cases being malignant. Ovarian serous cystadenomas are rare in children. A 14-year-old presented with severe abdominal pain and abdominal distention. She underwent emergency laparotomy and surgical removal, the mass was found to be torsion of ovarian serous cystadenoma-fibroma on histology. In conclusions, germ cell tumours the most important causes for the giant ovarian masses in children. Epithelial tumours should not be forgotten in the differential diagnosis.
\end{abstract}

Keywords: Adolescent, Cystadenoma, Ovarian Cysts/diagnosis, Ovarian cystadenoma, Ovarian Neoplasms/surgery, Serous/surgery

\section{INTRODUCTION}

During infancy and adolescence, which are hormonally active periods of development cystic lesions of the ovary are most common. ${ }^{1}$ Cysts are mostly non-neoplastic in children and could be categorized as follicular, simple, and corpus luteum cysts. ${ }^{1}$ Ovarian cysts rarely grow immense. Ultrasonography scanning permits early detection and appropriate treatment. Occasionally, ovarian cysts reach enormous dimensions without raising any symptoms. A few cases of giant ovarian cysts have been sporadically reported in the literature. ${ }^{1}$

We presented a case of a giant ovarian cyst with torsion in a 14-year old girl, with characteristics of ovarian serous cystadenoma-fibroma both grossly and microscopically.

\section{CASE REPORT}

The patient is a 14-year-old female who presented at our gynac emergency with acute pain in abdomen colicky in nature associated with 2 episodes of vomiting. She gave history of blunt trauma to abdomen 5 days back after which she noticed abdominal distension. She had constipation since 15 days. She had no previous history of any illnesses, allergies or operations. She had normal regular menses. On general examination she weighed 42 $\mathrm{kg}$ and vital signs were normal. There was no icterus, edema, or lymphadenopathy. Abdominal examination showed general abdominal distension with 32 weeks size mass, tense, cystic in consistency. Intestinal sounds were normal. External genital examination was normal. Abdomino-pelvic ultrasonography was suggestive of a large $18.7 \times 14.5 \mathrm{~cm}$ cyst in the abdominopelvic region extending into right adnexal region. No intrinsic calcification or solid components, bowel loops are 
displaced to the sides and uterus was normal but compressed by mass.

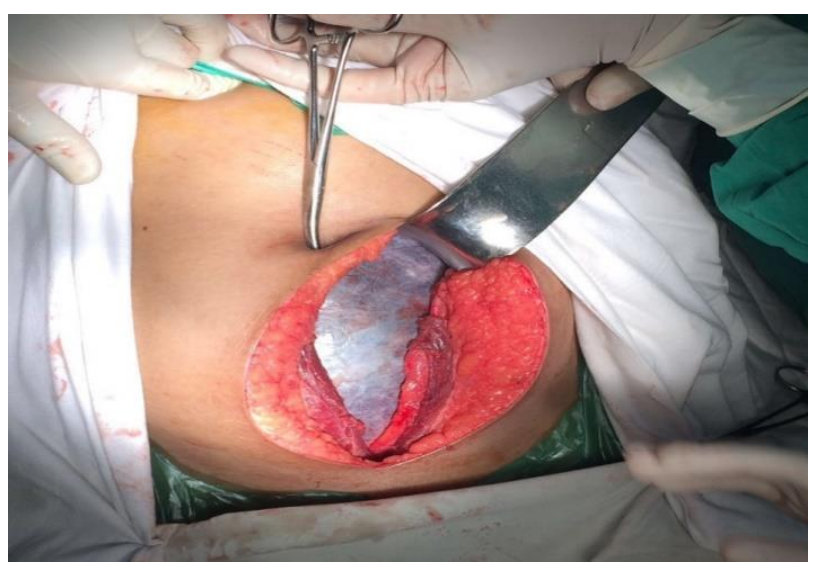

Figure 1: Midline vertical incision.

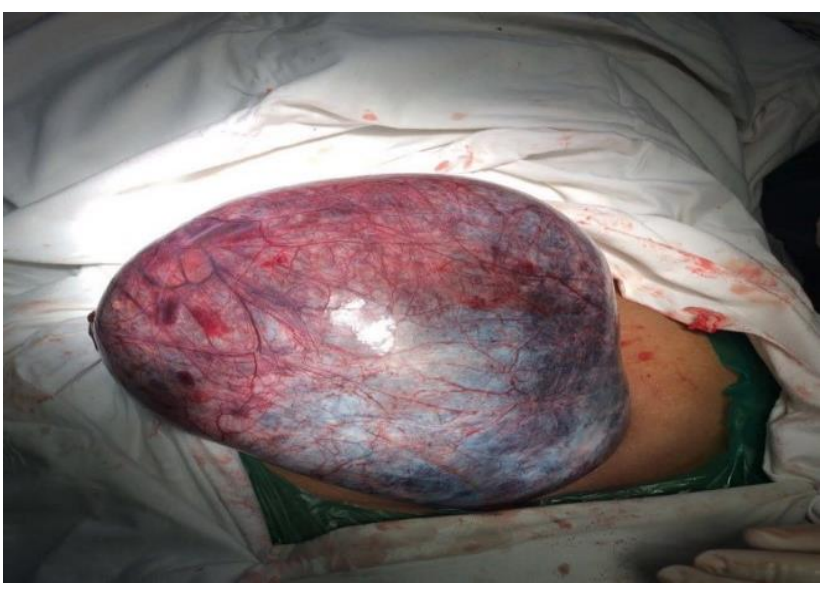

Figure 2: Huge right ovarian cyst.

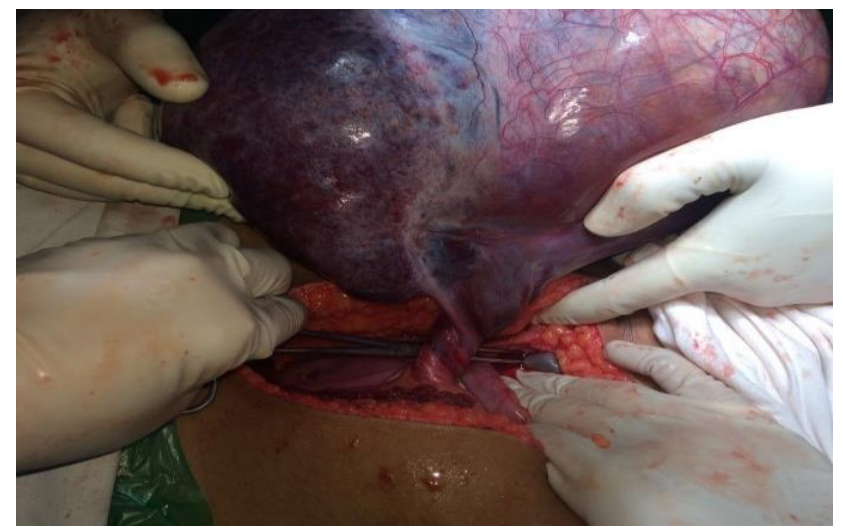

Figure 3: Huge right ovarian cyst with torsion (360 degree) of pedicle.

The patient underwent emmergency laparotomy with a vertical midline incision, under and up to the umbilicus (Figure 1). After opening the layers, a large tense, smooth- surfaced cystic mass was noted. The mass was removed from the incision (Figure 2). The cyst measured $20 \times 11 \times 9 \mathrm{~cm}$, extended up to the undersurface of the left diaphragm, and totally weighed $3.5 \mathrm{~kg}$. The mass originated from the right ovarian region with 360 degree of torsion of pedicle of cyst (Figure 3 ). We excised the cyst with ovary and the ipsilateral fallopian tube as it is adherent and stretched out over ovarian cyst (Figure 4). The left ovary and fallopian tube was explored and normally noted. There was minimal fluid in the abdomen.

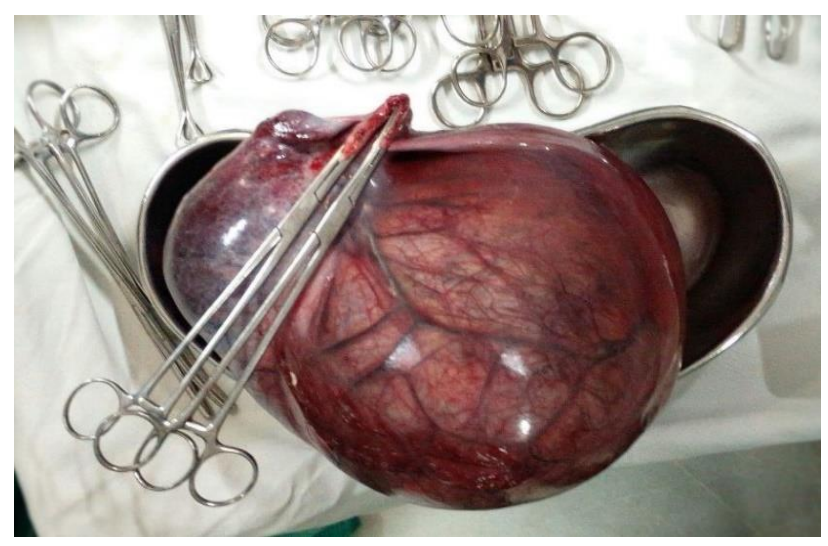

Figure 4: Huge right ovarian cyst

(20 $\times 11 \times 9 \mathrm{~cm}$ in size).

In pathologic examination, cyst was lined by flattened to low cuboidal epithelium with few papillary configurations with fibrous proliferation with fresh and old hemorrhages sign of benign serous cystadenofibroma with torsion (Hematoxylineosin stain, original magnification, X 100). Peritoneal fluid cytology shows RBC, neutrophils, histiocytes in proteinaceous background with no malignant cells. The postoperative period was uneventful and the patient was discharged on the fifth day after the operation.

\section{DISCUSSION}

Ovarian neoplasms may be divided according to original cell types into three main groups: epithelial, stromal, and germ cell. The epithelial tumors are the most common type. The single most common benign ovarian neoplasm is the benign cystic teratoma; however, according to some studies, it is serous cystadenoma. The most common types of epithelial neoplasms encountered were benign cystadenoma, of which $75 \%$ were serous and $25 \%$ were mucinous. ${ }^{2}$ Serous or mucinous cystadenomas of the ovary, benign or malignant, are rare in children. They arise from mullerian germinal epithelium. Patients are usually post-pubertal. ${ }^{2}$

Children with an ovarian mass might have no symptoms, and the mass might be detected incidentally or during a routine examination. Other children present with lower abdominal pain or an increase in abdominal girth that may be accompanied by nausea, vomiting, dysuria, increased urinary frequency, urinary retention, constipation, weight loss, menstrual abnormalities, dyspnea, orthopnea, ascites, supine hypotension, hydronephrosis, or pleural effusion. ${ }^{3}$ Ovarian masses in 
children more frequently are associated with acute complications such as torsion, hemorrhage, and rupture. ${ }^{2}$ Torsion of the ovary usually occurs with torsion of the fallopian tube as well on their shared vascular pedicle around the broad ligament, although in rare cases the ovary rotates around the mesovarium or the fallopian tube rotates around the mesosalpinx. In $80 \%$, torsion happens unilaterally, with slight predominance on the right. ${ }^{4}$

In (pre) pubertal girls, the differential diagnosis with functional cysts can involve some delay. A functional cyst is mainly a unilocular and anechoic cyst with thin borders. Second differential diagnoses of ovarian cysts are omental cysts. Omental cysts occur in all age groups, but most often they present in children and young adults. Other diagnoses may be mesenteric cysts, cysts arising from retroperitoneal structures like pancreatic pseudocysts, urinary retention, bladder diverticulum, hydronephrosis, cystic lymphangiomas, choledochal cysts, splenic cysts, multicystic dysplastic kidney, gastrointestinal duplication cysts and large uterine tumors. $^{5}$

Management of ovarian cysts depends on the patient's age, the size and structure of the cyst and menopausal status. Surgical management of cysts is by laparotomic or laparoscopic cyst excision or cystectomy with oophorectomy. In addition, the contralateral ovary should be examined and where it looks suspicious, a frozen section will assist in deciding whether to remove it or not. ${ }^{6}$ Some authors have emphasized that intact cyst removal, with gradual rolling of the mass off the inferior vena cava, is the optimal technique. On the contrary, Hunter et al have reported that gradual decompression prevents rupture of the cyst capsule and greater dissemination. ${ }^{7}$

The potential complication of repeated paracentesis is the intraperitoneal spillage of cyst components. This could result in tumor seeding of the peritoneal cavity or paracentesis tract if the cyst is malignant. Other complications associated with repeated paracentesis include infection, bleeding, and an increase in the number and density of peritoneal adhesions, making eventual cyst removal even more difficult. ${ }^{8}$ In the cases of emergency surgery that do not allow waiting for results of tumor markers, decision of choice, laparoscopy versus laparotomy, can be based on size and structure of the enlarged ovary. ${ }^{9}$ Low malignant recurrences have been reported more than ten years after initial surgery in the adult patient population, so it may be safe to assume that those diagnosed in adolescence should be observed into adulthood. Although adherence to long-term follow-up can be difficult, this should not alter the decision to perform a conservative surgical procedure in an attempt to preserve a patient's fertility. ${ }^{10}$

\section{CONCLUSION}

In conclusion, we had known that germ cell tumors are the most important causes for giant ovarian masses in children. But epithelial tumors should not be forgotten in the differential diagnosis.

Funding: No funding sources

Conflict of interest: None declared

Ethical approval: Not required

\section{REFERENCES}

1. Brandt ML, Helmrath MA. Ovarian cysts in infants and children. Semin Pediatr Surg. 2005;142:78-85.

2. Paran ST, Mortell A, Devaney D. Mucinous cystadenoma of the ovary in perimenarchal girls. Pediatr Surg Int. 2006;22:224.

3. Schultz KA, Sencer SF, Messinger Y, Neglia JP, Steiner ME. Pediatric ovarian tumors: a review of 67 cases. Pediatric Blood Cancer. 2005;44(2):167-73.

4. Katke RD, Gohil D. Rupture and torsion of a huge ovarian cyst with ipsilateral para-ovarian cyst presented as haemoperitoneum and acute abdomen: A rare case report and review of literature. Int $\mathbf{J}$ Res Health Sci [Internet]. 2014;2(4):1170-3.

5. Wootton-Gorges SL, Thomas KB, Harned RK, Wu SR, Wexler SR, Strain JD. Giant cystic abdominal masses in children. Pediatr Radiol. 2005;35(12):1277-88.

6. Nwobodo EI. Giant mucinous cystadenoma: case report. Niger J Clin Pract. 2010;13(2):228-9.

7. Hunter DJS. Management of a massive ovarian cyst. Obstet Gynecol. 1980;56:254-5.

8. Kim YT, Kim JW, Choe BH. A case of huge ovarian cyst of 21- year-old young woman. J Obstet Gynaecol Res. 1999;254:275-9.

9. Vaysse C, Delsol M, Carfagna L, Bouali O, Combelles $\mathrm{S}$, Lemasson F. Ovarian germ cell tumors in children. Management, survival and ovarian prognosis. A report of 75 cases. J Pediatr Surg. 2010;45(7):1484-90.

10. Aggarwal A, Lucco KL, Lacy J, Kives S, Gerstle JT, Allen L. Ovarian epithelial tumors of low malignant potential: a case series of 5 adolescent patients. J Pediatr Surg. 2009;44(10):2023-7.

Cite this article as: Khade SA, Shirodkar S. Ovarian huge serous cystadenoma with torsion in adolescent girl: a case report. Int J Reprod Contracept Obstet Gynecol 2017;6:1151-3. 